Western University Scholarship@Western

2006

\title{
Terminological Reflections of an Enlightened Contextualist
}

Robert J. Stainton

University of Western Ontario, rstainto@uwo.ca

Follow this and additional works at: https://ir.lib.uwo.ca/philosophypub

Part of the Linguistics Commons, and the Philosophy Commons

Citation of this paper:

Stainton, Robert J., "Terminological Reflections of an Enlightened Contextualist" (2006). Philosophy Publications. 39.

https://ir.lib.uwo.ca/philosophypub/39 


\section{Terminological Reflections of an Enlightened Contextualist ${ }^{1}$ \\ Robert J. Stainton \\ University of Western Ontario}

In preparation for Philosophy and Phenomenological Research

\section{Introduction}

From the perspective of certain contextualists, the most worrisome theses of Cappelen \& Lepore's Insensitive Semantics would seem to be:

T1: The only context sensitive items are the basic and obvious ones, i.e., pronouns, demonstratives, etc.;

T2: Once referents are assigned to these basic and obvious items in a (declarative) sentence, that sentence has truth conditions;

T3: This truth-conditional content is asserted when the sentence is used;

T4: The content of the assertion made is not thereby fixed, however, because speech act content depends upon features beyond the utterance context;

T5: The relativized truth conditions are psychologically relevant.

In particular, these theses seem to conflict directly with contextualism as defended by such authors as Robyn Carston, François Récanati, and Dan Sperber \& Deirdre Wilson.

Appearance of conflict notwithstanding, I will urge that the disagreements between Cappelen \& Lepore (henceforth, C\&L) and such contextualists aren't quite what they seem. The game plan is this. I will rehearse some distinctions corresponding to the bold-faced terms in T1-T5. I then use these distinctions to present a strategy for defending an "enlightened contextualism": a view that grants these four theses, yet holds fast to certain core commitments of contextualism. (I do so, to put my own cards on the table, because I am a steadfast contextualist, yet I find C\&L's arguments important, insightful and persuasive - thus I'd like to find a way to make them compatible.)

A few clarifications, before I begin. First, my suggestion is emphatically not that Carston et al. have accepted T1-T5; still less is it that no disagreements remain once the terminology is sorted out. (This point will be reinforced at the end.) Second, because space is at a premium, I will not defend the distinctions drawn, nor will I attribute the various uses of the bold-faced terms to any author(s) in particular. For the same reason, I

\footnotetext{
${ }^{1}$ I am grateful to Ray Elugardo, Ernie Lepore and Catherine Wearing for comments on an earlier draft.
} 
will only sketch a strategy for defending an enlightened contextualism: a full-dress defense would require far more. Be forewarned, as well, that I don't endorse all the ways these terms are in fact deployed: some uses strike me as downright misleading. But my task here is to highlight senses/uses, not to criticism them. Speaking of 'senses' and 'uses', I don't think much hangs on whether the terms in question really have multiple senses, or whether theorists just use them differently, hence I will slide between 'senses' and 'uses' in what follows.

\section{The Terminological Reflections}

Start with 'context sensitive'. One thing a philosopher can mean by so labeling a word is that it is a speaker-context magnet. That is, it's the kind of word which (except in direct discourse) inevitably finds its in-context referent in the speaker-context, regardless of how deeply embedded it is. 'I', 'now', and 'here' are familiar examples. No matter what

complex story is told, no matter how deeply the word 'now' is embedded syntactically, if it isn't directly quoted, its referent will be, well, now. Consider Patty, who says: 'John was very drunk last night, and terrifically confused about the time. He said he wouldn't be here now'. Spell it out as you wish, it still seems like 'now' is the time at which Patty spoke, not the time John did, nor the time he confusedly intended. (Similarly for 'here'.) Another sense of 'context sensitive' is that the expression's in-context reference is somehow relative to a feature of the utterance context: its extension changes in some fashion even while holding "the evaluation world" constant. (Compare C\&L's definition on p. 89 and 99.) Obvious cases include 'left' and 'right': if I say, 'I hereby give Herman the car on the left', which car I gave him depends on how I am oriented towards the automobiles in question, and not because 'left' is ambiguous. Somewhat less obvious examples include 'second' (as in, 'Turn at the second set of lights') and 'peso' (which can be used to refer to various currencies, with the referent depending on speaker context - though, I insist, 'peso' is not ambiguous). The least obvious relative terms are the ones scientists find out about: e.g., 'weighs precisely six pounds' is satisfied by different classes of things depending upon the gravitational force at work in the situation that the speaker is talking about. (Note: the word 'situation' is important here. The possible world must remain constant, otherwise the evaluation world has been changed. What alters must 
only be which part of the evaluation world is being discussed.) A third, and weaker, usage of 'context sensitive' has to do with pragmatic determinants of what is asserted, stated, or claimed. In this sense, to call a word context sensitive is just to say that, even after disambiguation, it can be used to assert, state or claim that various properties are instantiated. Take 'weapon'. In an utterance context where a law has been passed banning all weapons in public buildings, Andreas could say of his archive: 'There are no weapons in this building', and speak truly -- even though a rock which was once used in a murder is stored there. In contrast, if the police are drawing up a comprehensive record of which murder weapons are stored where, Andreas' utterance about his archive would be false. Not because the rock or anything else had been moved, or otherwise changed its properties, but because the property literally asserted/claimed to hold, using 'weapon', is different... because of the utterance context. (Or so says the believer in this kind of context sensitivity.) For those who accept that pragmatics frequently affects speech act content, this third sense is quite weak: pretty much any word can be so used, so virtually any word is "context sensitive" in this sense. Yet the final way of understanding "context sensitive' that I want to highlight is weaker still. To call a word context sensitive in this sense is to say that various things count as falling in its extension. That means something like: given the utterance context, we would reasonably treat them as such (even if they aren't strictly instances). For instance, in a legal context we might reasonably count shrimp, squid and lobster as fish, even though they are not strictly speaking fish at all. In sum, we have:

\section{Senses of 'Context Sensitive'}

a) Speaker-context magnet

b) Relative to utterance context somehow

c) Useable to assert different properties

d) Reasonably counting as ${ }^{2}$

The most complex of the distinctions is next: having truth conditions. On the first sense, a disambiguated expression has truth conditions just in case it is true or false tout

\footnotetext{
2 To further bring out the differences here, note two things. First, it's doubtful that expressions which are "context sensitive" in the last three senses pass C\&L's tests, in Chapter 7. Second, whereas the senses (a) and (b) are specific to particular lexical items, (c) and (d) are not. (By the way, this is one place where I do not endorse a usage that I describe: I myself would not call words to which (c) and (d) alone apply 'context sensitive items'.)
} 
court. That is, the expression type partitions the set of worlds into two classes: every world satisfies either the sentence or its negation, and no world satisfies both. I hope this is a sense of 'truth condition' that no one endorses for natural language expressions. Even many declaratives don't have truth conditions in this sense, not least because they contain speaker-context magnets. But introducing this sense is useful because it highlights that everyone weakens their notion of truth condition somewhat - compared, say, with what might be found in a classical logic. The second sense is this: a disambiguated expression type has truth conditions only if it is true or false - it partitions the worlds -- relative to a set of previously established parameters. Example parameters include speaker and addressee (for 'I' and 'you'), objects, times and places demonstrated (for 'this', 'that', 'then' and 'there'), utterance time (for 'now', 'today', 'yesterday', and tense), place of utterance (for 'here'), and world of utterance (for 'actual'). This is not merely the idea that a sentence has truth conditions if it is true or false "relative to the context of utterance": what a context is must be highly restricted for this sense of 'having a truth condition' to apply. The third notion, in contrast, precisely is that a sentence, to have a truth condition, must be true or false relative to "Big Context": the whole panoply of intentions, facts, etc., at the moment of utterance. To see the contrast, take 'Ernie Lepore arrived late'. Even relativized to the above list of parameters, it does not seem to partition the set of worlds. (Assigning July 15, 2005 at 3:45 p.m. EST as the referent for tense, thereby fixing all relevant parameters, is the result satisfied by worlds such that Ernie arrived late for a meeting with his Dean, but was on time for his classes?) In contrast, together with "Big Context" this sentence might well partition the worlds. The fourth notion is hard to spell out. There is a felt difference between sentences in which a metaphysically required element is not specified, and sentences in which a linguistically inherent element is omitted. (Compare p. 66 of Insensitive Semantics.) For instance, the action of following must happen somewhere, at some pace, for some reason. These are metaphysically required elements of any act of following. In contrast, who or what was followed, the object of 'follow', seems in some sense to be (not just metaphysically but) linguistically required - this despite the fact that 'Robyn followed' is syntactically wellformed. Whatever lies behind this felt difference - something in syntax/semantics, or something else again -- we get a notion of having versus not having truth conditions: a 
sentence lacks truth conditions if one of its linguistically inherent elements is omitted, but it has truth conditions if all of them are specified, even if certain metaphysically required elements are not filled in. The final use of 'truth condition' of interest here is the Tarskiian one: any sentence which yields a well-formed and meaningful instance of the T-schema has truth conditions. (Relative, of course, to the pre-established list of parameters. $)^{3}$ For example, even 'Canada lost' and 'Ernie arrived late' have truth conditions in this final sense, once a time is specified for tense, because " Canada lost' is true iff Canada lost" and "'Ernie arrived last' is true iff Ernie arrived late" are both syntactically well-formed and sense-bearing. To summarize:

2. Senses of 'Truth Condition'

a) True or false tout court

b) True or false relative to a fixed set of parameters

c) True or false relative to "Big Context"

d) Not missing any linguistically required elements

e) Having a corresponding Tarskiian T-sentence

Before moving on, a word is in order about the attractiveness of this last notion. One can't help but grant to C\&L that there's something fishy about the "felt difference" (pp. 43ff, 61, 65 and 67). We cannot rely on such a maleable intuition, one might reasonably insist, to provide a contrast being "genuine" propositions and sub-propositional schemas. As for "Big Context", inquiring whether something has truth conditions and if so what they might be, while applying this sense of 'truth condition', becomes utterly intractable. It also seems that partitioning the worlds in two, even relative to certain parameters, is too much to demand for being a genuine proposition: the kinds of cases that Charles Travis has made us all aware of suggest that no pre-established set of parameters will do that. The great virtue of sense (2e), then, is that it affords a clear diagnostic for being genuinely propositional, and one which is not subject to Travis' slippery slope. (My one worry about it is that it seems to make having truth conditions too cheap: for instance, 'Uruguay did' and 'Herman will' seemingly both come out as having truth conditions. But let's set that aside.)

\footnotetext{
${ }^{3}$ The caveat about being meaningful blocks “' Colorless green ideas sleep furiously' is true iff colorless green ideas sleep furiously". In addition, if one thinks that 'John cut the sun' has no literal meaning, it is ruled out by this too.
} 
Now for 'assertion'. Two relevant uses of it come immediately to mind. The first is tied closely to the speaker's psychological attitudes. On this sense, one asserts only those propositions which one means $_{\mathrm{NN}}$; so, given that meaning $\mathrm{NN}_{\mathrm{N}}$ involves lots of intentions, one asserts only what is intended. (This is emphatically not to say that one asserts all the things meant $\mathrm{NN}_{\mathrm{N}}$ : e.g., one does not assert things which are merely conversationally implicated. More on this immediately below.) Another connection to the speaker's psychology has to do with norms: the speaker should believe, and maybe even know, what she asserts, in this first philosophical usage of 'assert'. Resulting from this close tie to psychological attitudes, the things asserted can be (though they needn't be) de dicto. Thus, on this first sense, a person may assert, for instance, that the Queen of England is attractive, without thereby asserting that Canada's Head of State is attractive -- even though Elizabeth II occupies both of these roles. Though intention-oriented, this use of 'assertion' needs to make some appeal to the standing meanings of expressions as well: given the right set up, people can convey just about anything with the sentence 'Jason is deeply mistaken', but what they can assert with this sentence, at least in the first sense of 'assert', is far more constrained; and a big part of what imposes the constraints, in my view, is expression-meaning. The second philosophical use of 'assertion' is not subject to the belief/knowledge norm; it isn't especially sensitive to the standing meaning of the words used by the speaker; still less is it keyed to what the speaker meant $\mathrm{NN}_{\mathrm{N}}$ de dicto. In this sense, instead, a proposition $p$ is asserted by a speaker $S$ as soon as a report of the form " $S$ said that $p$ " is correct. (I leave open whether 'correct' should be read as 'merely true', 'merely warranted', 'true and warranted', etc., but I note that especially if the latter two are intended, "what was asserted by $S$ " will clearly be relative to the situation in which the report is made.) In sum:

\section{Senses of 'Assertion'}

a) Intention-oriented

b) Report-oriented

Now, finally, for 'psychologically relevant'. This, of course, has many, many senses. But, since space is running short, I will flag only two. One is the idea that a piece of information is psychologically relevant just in case it is at the agent's cognitive disposal: it can be accessed; it can be made consciously available; it could be used in processing. 
Call this (4a). The contrasting sense is about actual on-line processing: the information $I$ is psychologically relevant in interpretive situation $S$ only if the agent occurrently makes use of $I$ in $S$. Call this (4b).

\section{Towards Enlightened Contextualism}

I have introduced five theses that seemingly conflict with (my preferred variant of) contextualism, and have indulged in terminological reflections on four key terms in those theses. Please grant, for the remainder, that my distinctions hold up to scrutiny. The next and final step is to present a strategy, drawing on those distinctions, for rendering the five theses consistent with certain core commitments of contextualism. (Holding onto the latter makes one a contextualist; acceding to the former makes one an enlightened contextualist.)

Let me make the seeming conflict fully explicit by listing five theses that I would take to be at the core of my kind of contextualism:

CC1: Context sensitivity is ubiquitous;

CC2: Sentences typically do not have truth conditions, even once relativized;

CC3: That content which derives from expression-meaning plus assignment of referents according to fixed parameters, the so-called "minimal proposition", is not generally asserted;

CC4: Asserted content is fixed by utterance context, including especially the conversational participants' mental attitudes;

CC5: The so-called "minimal proposition" is not psychologically relevant.

The strategy for holding onto these in the face of Insensitive Semantics, not surprisingly, is to maintain that each T-series thesis is true on one sense of its bold-faced term, but to insist that so read the thesis is not inconsistent with the CC-series theses.

In particular, T1 is true on sense (1a) of 'context sensitive', the speaker-context magnet sense; T2 is true on sense (2e) of 'truth condition', the Tarskiian sense; T3 and $\mathrm{T} 4$ are both true on sense (3b) of 'assertion', the report-oriented sense; and T5 is true on sense (4a) of 'psychologically relevant', the "it's accessible" sense. The idea, however, is that $\mathrm{CC} 1$ is nevertheless true on sense (1c), for, so read, $\mathrm{CC} 1$ merely acknowledges pragmatic determinants of what is asserted, and that's something that $C \& L$ themselves 
endorse. (More than that, CC1 is clearly (and boringly) true on sense (1d), the "reasonably counting as" sense. In addition, I would argue given space that T1 is false on sense (1b): there are context sensitive expressions that aren't speaker-context magnets.) $\mathrm{CC} 2$ is true on sense (2b): relativized sentence types don't partition the worlds. (Again, given space I would argue that T2 is false on sense (2d), since some syntactically wellformed declarative sentences are linguistically incomplete, semantically speaking - hence they do not have truth conditions in this sense.) Continues the strategy: one can, consistent with T1-T5, hold that CC3 and CC4 are true on sense (3a), the intentioncentered sense of 'assertion'. ${ }^{4}$ Finally, CC5 is true on sense (4b): where there is a minimal proposition, it doesn't generally play a part in occurrent on-line processing.

If the strategy succeeded, would the result be that everyone ultimately agrees the enlightened contextualist with $\mathrm{C} \& \mathrm{~L}$, and they with everyone else? By no means. There are disagreements about details even between C\&L and the enlightened contextualist: some appeared immediately above, e.g., whether T1 is true on sense (1b) of 'context sensitive', and whether T2 is correct on sense (2d) of 'having truth conditions'. There will also be disagreements, among the disputants in this general domain, about what is done by phonologically null elements of syntax, what by semantics, and what by pragmatics alone. More centrally, there are deep disagreements about the project between: Are we trying to model natural languages, understood as systems of expressions, or are we modeling human psychological processing of language in context? Related to this, I think, is a disagreement about the comparative usefulness and viability - for the cognitive sciences -- of a semantics that translates natural language into mental representations, versus any semantics that assigns worldly items of some sort to expressions. This, I think, may be the real source of Carston et al.'s resistance to truththeoretic semantics: not that it makes the wrong predictions about which things have truth

\footnotetext{
${ }^{4}$ Two asides about the "minimal proposition". First, I think one should read contextualist claims about such propositions "not existing" as loose talk, amounting to: "such things don't partition the set of worlds, and they don't play a role in processing". Second, C\&L contend that communication is impossible without a minimal proposition, since only it provides something to (dis)agree about. This seems wrong on several fronts: (i) communication succeeds when sub-sentential assertions take place, but there is no minimal proposition in that case; (ii) conversational participants don't merely (dis)agree about the minimal proposition, they also frequently (dis)agree about what is asserted, stated, etc.; (iii) communication often enough succeeds in particularized conversational implicature, and the minimal proposition can't be the key to that.
} 
conditions, and what they are, but rather that it's unhelpful qua contribution to cognitive science. (At any rate, that is a worry of the present enlightened contextualist.) More specifically, if our main business is describing the linguistic system, a truth theoretic statement of truth conditions may be fine. If we are trying to understand processing, however, T-sentences seem otiose at best: surely I do not process an utterance of 'Jason is deeply mistaken' by deploying the T-sentence “'Jason is deeply mistaken' is true iff Jason is deeply mistaken". (If I already know what 'Jason is deeply mistaken' means, which I must if the right-hand side of the T-sentence is to be useful, why bother generating a T-sentence as part of the on-line processing? And if I don't already know what it means, how can the T-sentence help me?)

In sum, if the distinctions I have laid out are accepted, we may find a place for an enlightened language theorist who grants many of Cappelen and Lepore's insights, including in particular their cogent arguments for T1-T5, while holding fast to the core values of an old-fashioned contextualism, specifically CC1-CC5. Even doing so, there is plenty left to disagree about; but the disagreements between C\&L and (some of) their targets might not turn out to be quite what they first seemed. 